\title{
Impact of shield tunneling on adjacent spread foundation on sandy cobble strata
}

\author{
Yong Fang $\cdot$ Jun Wang $\cdot$ Chuan He $\cdot$ \\ Xiongyu Hu
}

Received: 8 January 2014/Revised: 16 October 2014/ Accepted: 20 October 2014/Published online: 31 October 2014

(C) The Author(s) 2014. This article is published with open access at Springerlink.com

\begin{abstract}
The section of shield tunnel of the Chengdu Metro line passes primarily through sandy cobble strata. There are many buildings with spread foundations along the lines. Shield tunnel construction will disturb the ground, causing displacement or stress to adjacent spread foundations. Based on the similarity theory, a laboratory model test of shield tunnel driving was carried out to study the influence of shield tunnel excavation on the displacement of adjacent spread foundation. The results show that foundation closer to the tunnel has greater displacement or settlement than that further away. The horizontal displacement is small and is influenced greatly by the cutting face. The displacement along the machine driving direction is bigger and is significantly affected by the thrust force. Settlement occurs primarily when shield machine passes close to the foundation and is the greatest at that time. Uneven settlement at the bottom of the spread foundation reaches a maximum after the excavation ends. In a numerical simulation, a particle flow model was constructed to study the impact of shield tunnel excavation on the stresses in the ground. The model showed stress concentration at the bottom of the spread foundation. With the increasing ground loss ratio, a loose area appears in the tunnel dome where the contact force dropped. Above the loose area, the contact force increases, forming an archshaped soil area which prevents the loose area from expanding to the ground surface. The excavation also changed the pressure distribution around spread foundation.
\end{abstract}

Y. Fang $\cdot$ J. Wang $\cdot$ C. He $(\bowtie) \cdot$ X. Hu

Key Laboratory of Transportation Tunnel Engineering, Ministry of Education, Southwest Jiaotong University, Chengdu 610031, China

e-mail: chuanhe21@163.com
Keywords Shield tunnel $\cdot$ Sandy cobble strata $\cdot$ Spread foundation - Distinct element method - Model test

\section{Introduction}

An earth pressure balance (EPB) shield machine was used in the construction of the Chengdu Metro tunnel in China. The tunnel passes mostly through sandy cobble stratum which features low cohesion, point-to-point contact, and high sensitivity to ground reaction. The original equilibrium state of the strata can be easily destroyed by shield tunnel construction and the considerable ground disturbance involved in the process. The Chengdu Metro tunnel passes under an urban area that includes shallow underground foundations, which are widely used in the construction of residential housing, flyovers, and multistory buildings.

The effect of shield tunnel construction on the environment has been studied both in theory and practice. Peck [1] developed the concept of ground volume loss and proposed a method to estimate ground surface settlement in a transverse section based on a large number of field studies. Sagaseta [2] gave a solution for the stress field induced by near-surface ground loss in an initially isotropic and incompressible soil. Verruijt and Booker [3] proposed an analytic method for simulating surface settlement in homogeneous, elastic, semi-infinite space formed by tunneling. Ma and Ding [4] adopted the finite element method to study tunnel-soil-building interaction using a displacement controlled model. Huang et al. [5] developed a simplified method for analyzing the effect of tunneling on grouped piles. Chen et al. [6] studied ground movement induced by parallel EPB tunnels in silty soils. Although these methods can be applied to study the effect of shield tunnel construction in a continuous medium, they are not 
suitable for sandy cobble stratum that is typically a discrete medium.

Simple physical tests such as centrifuge model tests and similarity model testing were carried out to study the influence of shield tunnel construction. Bolton et al. [7] developed a method to simulate shield tunnel construction using drum centrifuge tests. Nomoto et al. [8] built a model shield machine for successive centrifuge tests. Loganathan et al. [9] carried out three centrifuge model tests to assess tunneling-induced ground loss and its effects on adjacent piles in clay soil. Soil with typical field characteristics is normally used in centrifugal tests. However, field soil cannot adequately represent the ground particle dimensions for sandy cobble stratum. It is difficult to meet the two requirements at the same time.

Kim et al. [10] developed a reduced-scale model test to study the effect of shield tunnel construction on the structural liners of existing nearby tunnels. Lu and Fu [11] carried out shield driving tests indoors in soft, sandy, and sandy cobble ground with a $\Phi 1,800-\mathrm{mm}$ EPB shield machine. Zhu et al. [12] used a $\Phi 400-\mathrm{mm}$ EPB model shield machine to carry out driving tests in soft ground within a $2.4 \times 2.4 \times 1.2 \mathrm{~m}$ cabin and obtained some significant results. However, these tests did not simulate the whole process of shield driving because they did not consider the lining segments and grouting. The counter force of the model shield machine comes from the rear supports such as the pipe-jacking rather than from the lining segments.

Because of its significant discreteness, the characteristics of sandy cobble stratum are not well represented in continuous medium numerical methods. The discrete element method is more suitable for studying the influence of shield tunnel construction in discrete medium. Maynar and Rodríguez [13] applied the particle flow code (PFC) method to investigate the thrust and torque of the EPB machine. Chen et al. [14] used the PFC method to study the face stability of a shallow shield tunnel in dry sandy ground. Zhang et al. [15] adopted the PFC method to study the face stability of slurry shield tunneling in soft soils. He et al. [16] combined the PFC method with model testing to study the effect of shield tunnel construction on adjacent pile foundation. In this paper, a test using a reduced-scale model which can simulate the process of shield tunnel construction was carried out to study its influence on the displacement of shallow adjacent building foundations. A 2D PFC model was built to assess the change of ground stress around the tunnel and the shallow foundation during tunnel construction.

\section{Project summary}

According to the construction plans of the Chengdu Metro line 1, the EPB shield machine will pass under the 20-year-
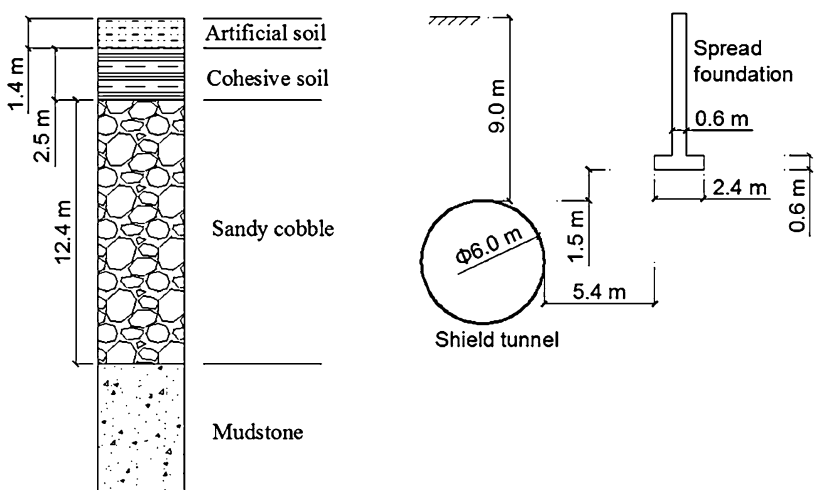

Fig. 1 Geological diagram and relative position between tunnel and spread foundation

Table 1 Mechanical parameters of strata

\begin{tabular}{llclll}
\hline Soil & $\gamma\left(\mathrm{kN} / \mathrm{m}^{3}\right)$ & $E(\mathrm{MPa})$ & $v$ & $\varphi\left({ }^{\circ}\right)$ & $c(\mathrm{kPa})$ \\
\hline Artificial soil & 17.0 & 3.0 & 0.39 & 10 & 10 \\
Cohesive & 19.0 & 6.0 & 0.30 & 27 & 21 \\
Sandy cobble & 22.0 & 38.0 & 0.31 & 38 & - \\
Mudstone & 23.0 & 60.0 & 0.21 & 41 & 70 \\
\hline
\end{tabular}

old Qinggong Building at mileage YCK7 +350 . The Qinggong Building is a shear-wall frame structure with extensive spread footing foundation in the sandy cobble stratum. The design load on the foundations is $860 \mathrm{kN}$. The minimum depth of the shield tunnel near this building is about $9.0 \mathrm{~m}$, and the shortest distances between the foundation and tunnel are 5.4 and $1.5 \mathrm{~m}$ in the horizontal and vertical directions, respectively. The outside diameter of the shield tunnel is $6.0 \mathrm{~m}$. The thickness and width of the segment lining are 0.3 and $1.5 \mathrm{~m}$, respectively. The position of the tunnel relative to the spread foundation is shown in Fig. 1, and the mechanical parameters of the strata are presented in Table 1, where $\gamma$ is the unit weight, $E$ the elastic modulus, $v$ the Poisson's ratio, $\varphi$ the friction angle, and $c$ the cohesive force.

\section{Model test of shield tunnel construction}

\subsection{Introduction of model shield machine}

\subsubsection{Model shield machine and control panel}

Compared to previous experiments conducted by $\mathrm{Lu}$ and Fu [11] and Zhu et al. [12], the model shield machine test in this experiment focuses more on the displacement rather than the interaction mechanism between the shield machine and the earth. Taking the city Metro shield tunnel as the prototype, our experiment used an EPB model shield machine with a scaling of $C_{L}=12: 1,\left(C_{L}\right.$ is geometric 


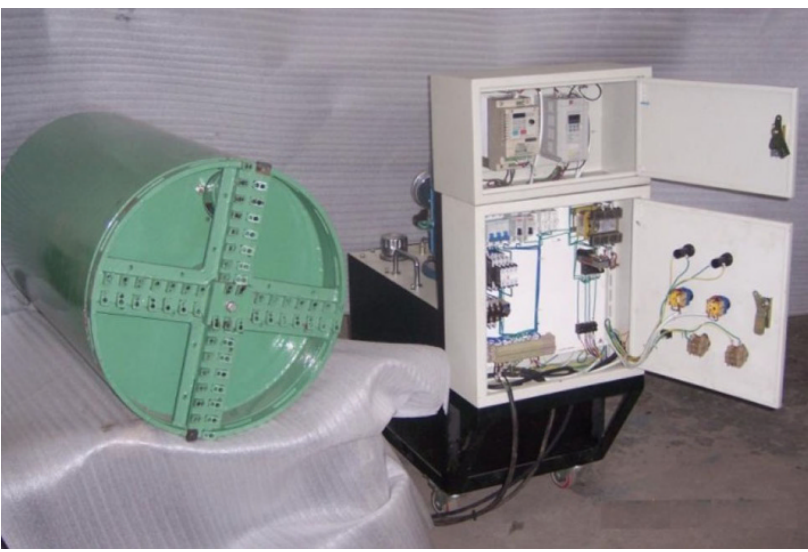

Fig. 2 Photos of EPB model shield machine

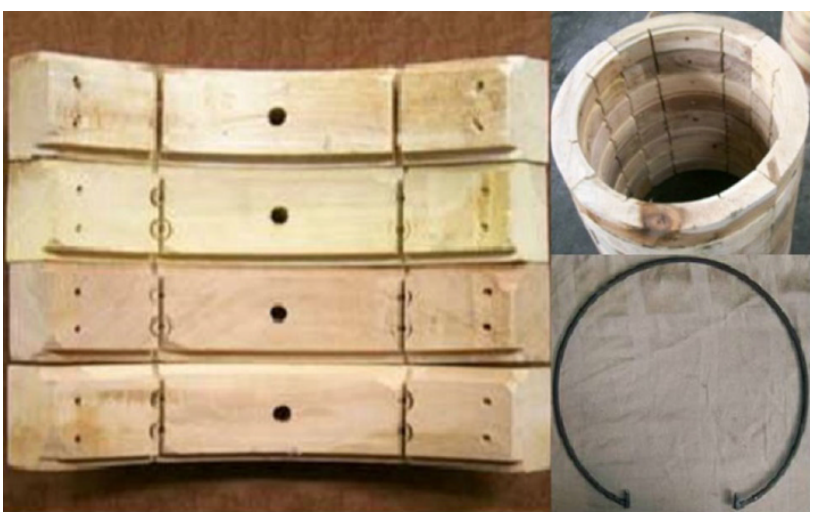

Fig. 3 Segment rings used in model test

similarity ratio). According to the similarity principle, the other similarity ratios are as follows:

$C_{E}=C_{c}=C_{u}=12, \quad C_{\gamma}=C_{v}=C_{\varphi}=1$,

where $C_{E}, C_{c}$, and $C_{u}$ are the similarity ratios of the elastic modulus, cohesive force, and displacement, respectively; $C_{\gamma}, C_{v}$, and $C_{\varphi}$ are the similarity ratios of the unit weight, Poisson's ratio, and friction angle, respectively. The outer and inner diameters of the shield, the tail void, and the outer diameter of the lining segments were determined proportionately. The length of the shield was designed according to the space for the inner equipment and segment installation. The model shield machine was $85 \mathrm{~cm}$ long with an inner diameter of $52 \mathrm{~cm}$ and outer diameter of $50.8 \mathrm{~cm}$. The cutting wheel overcut was $0.6 \mathrm{~cm}$, the shield thickness $0.6 \mathrm{~cm}$, and the outer diameter of the model segment was $50 \mathrm{~cm}$.

The machine includes mainly three types of sets: cutting, exhausting, and advancing. They are controlled separately via the control panel that can change the parameters of the model shield driving: rotation speed of the cutting head and screw, co-rotation or counter-rotation, thrust of

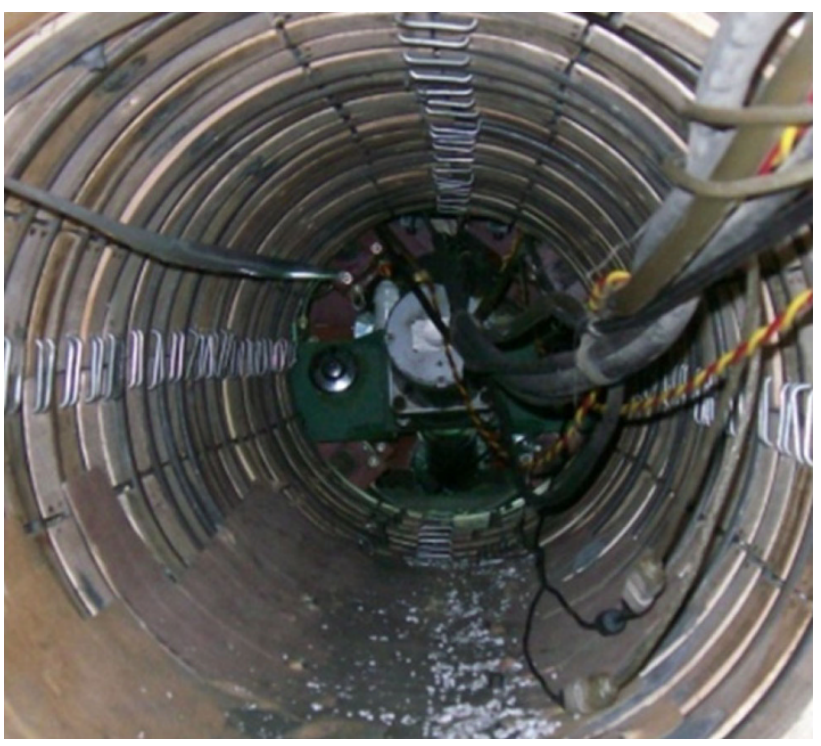

Fig. 4 Arranged segment ring during the driving

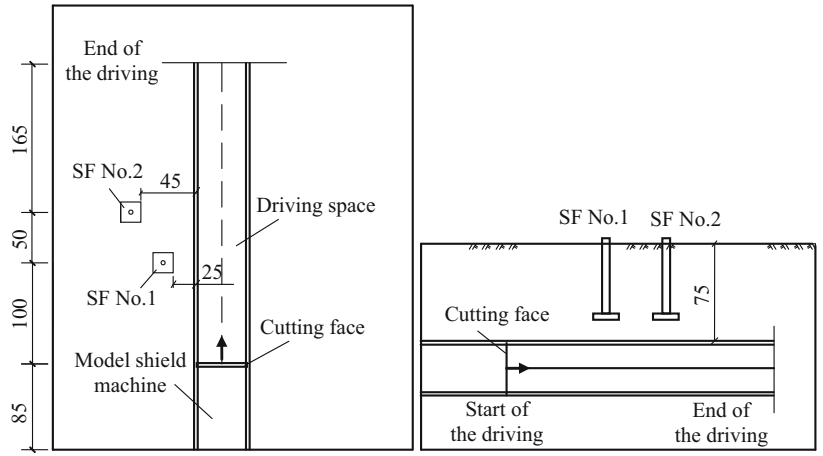

(a)

(b)

Fig. 5 Sketch of the model shield machine driving (unit: $\mathrm{cm}$ ). a Top view. b Side view

jack, and so on. Photos of the model shield machine and control panel are shown in Fig. 2.

\subsubsection{Cutting and exhausting apparatus}

The cutting apparatus includes the cutting head, bearing, and electric motor. The cutting head with an opening ratio of $54.5 \%$ is composed of spokes, cutters, and an outer ring. It is driven by an electric motor with a maximum torque of $500 \mathrm{~N} \cdot \mathrm{m}$. The exhausting sets include a screw conveyor and an electric motor. The screw conveyor is also powered by an electric motor with a maximum torque of $50 \mathrm{~N} \cdot \mathrm{m}$.

\subsubsection{Advancing sets}

The model shield machine advances with a thrust supplied by four hydraulic jacks which are fixed inside the shield 
Table 2 Material parameters of model test soil

\begin{tabular}{lllll}
\hline & $E(\mathrm{MPa})$ & $\gamma\left(\mathrm{kN} / \mathrm{m}^{3}\right)$ & $\varphi\left(^{\circ}\right)$ & $c(\mathrm{kPa})$ \\
\hline Model strata & 3.5 & 20.8 & 33.25 & 7 \\
\hline
\end{tabular}

Table 3 Material parameters of prototype and model

\begin{tabular}{ll}
\hline Parameters & Value \\
\hline (a) EA for column & \\
Prototype value (N) & $2.638 \times 10^{8}$ \\
Model value (N) & 148,380 \\
(b) EA for spread foundation & \\
Design value (N) & $4.746 \times 10^{8}$ \\
Model value (N) & 278,200 \\
\hline
\end{tabular}

machine at equal intervals. Each jack has a maximum thrust not less than $5 \mathrm{kN}$; thus, the total thrust is at least $20 \mathrm{kN}$.

\subsubsection{Ring segments and grouting}

Four wooden ring segments each with a diameter of $50 \mathrm{~cm}$, longitudinal width of $5 \mathrm{~cm}$, and thickness of $5 \mathrm{~cm}$ were fitted at the tail of the shield machine. The lining segments were joined by prefabricated nails which can simulate the action of an actual segment and ring joint. To increase the stiffness of the lining segment ring, a $\Phi 10-\mathrm{mm}$ flat steel ring was fixed tightly onto the inner face of each segment (see Fig. 3).

Grouting behind the model segment can prevent ground movement, enhance tunnel impermeability, and ensure the stability of the segment rings during the early and late stages of tunneling [17]. Grouting holes were drilled in each model segment, as shown in Fig. 3. A mix of gypsum and water was used to simulate the action of the grouting

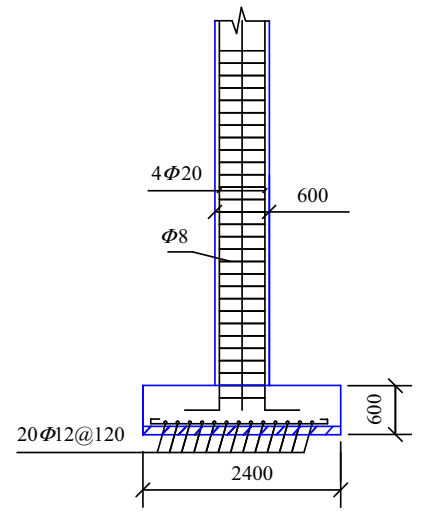

(a)

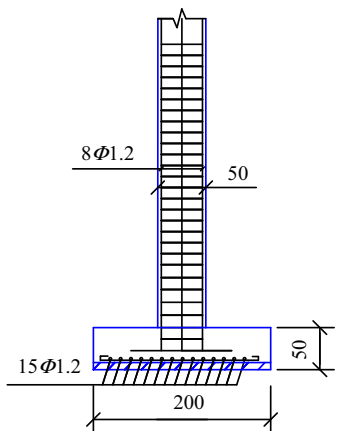

(b)
Fig. 6 Dimensions and reinforcement of spread foundation (unit:mm). a Prototype. b Model

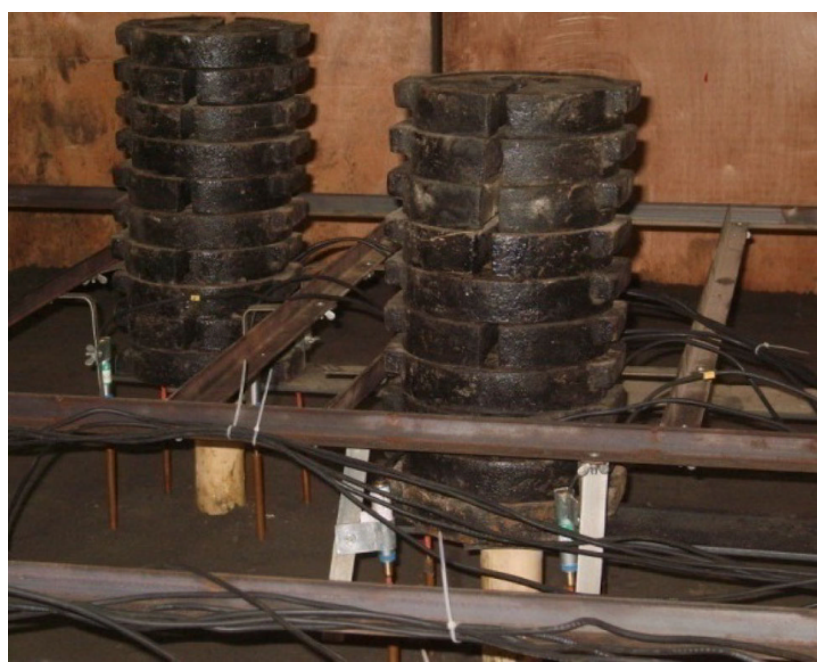

Fig. 7 Loads acting on the spread foundation

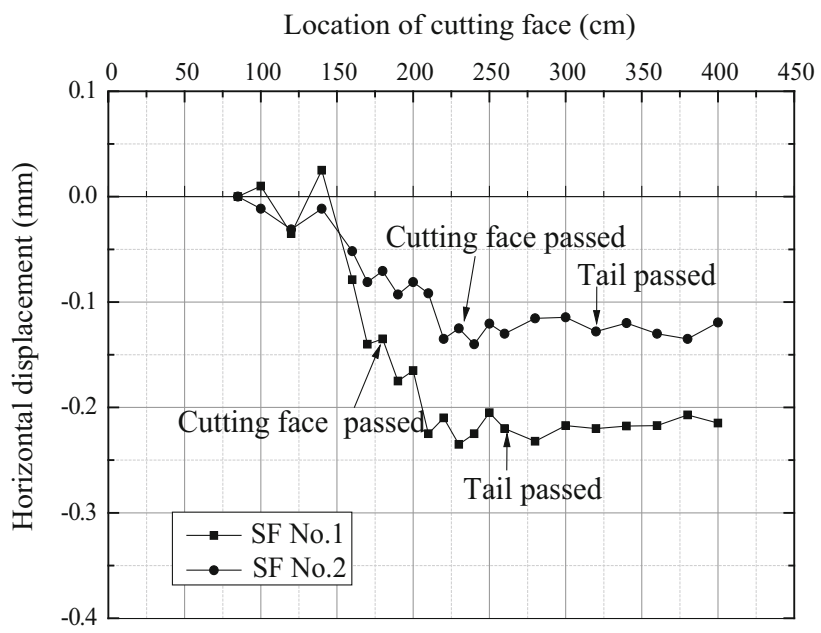

Fig. 8 Horizontal displacement of spread foundation during the excavation

material during the experiment. After the lining segments were arranged in place, gypsum was injected into the space between the lining segments and the ground. The assembled segment rings during the driving are shown in Fig. 4.

\subsection{Test bin and soil}

The size of the model test bin is determined by the dimensions of the model shield machine as well as the boundary of the shield driving on the ground. The dimensions of the test bin are as follows: length $460 \mathrm{~cm}$; width $420 \mathrm{~cm}$; height $300 \mathrm{~cm}$; depth of tunnel $75 \mathrm{~cm}$; and distance from tunnel center to the surface $80 \mathrm{~cm}$

In the experiment, the model shield machine was placed at a depth of $75 \mathrm{~cm}$ (Fig. 5). Spread foundation (SF) No. 2 represents the foundation of the Qinggong building scaled 


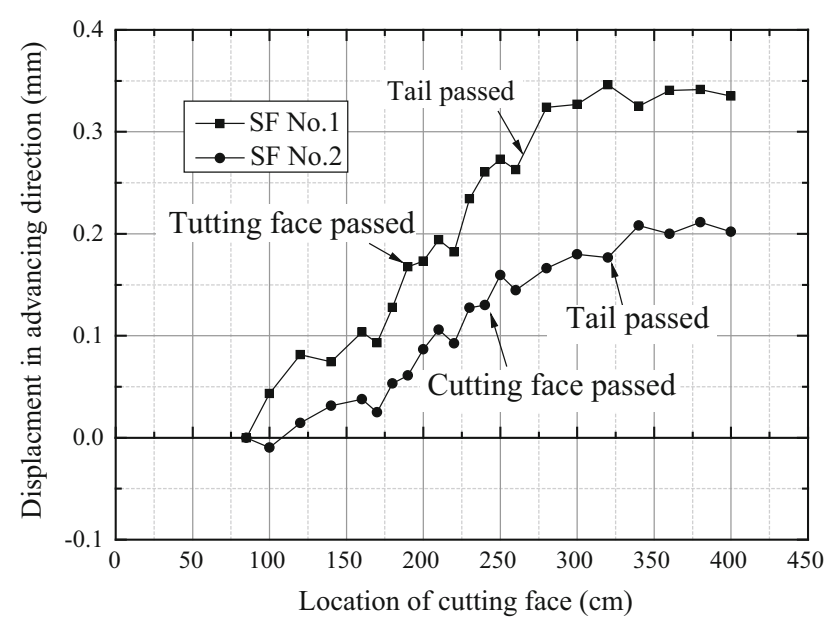

Fig. 9 Displacement in advancing direction during the excavation

down at $C_{L}=12: 1$, located $150 \mathrm{~cm}$ along the tunnel and $45 \mathrm{~cm}$ across from the cutting face. For comparison, SF1 was placed $100 \mathrm{~cm}$ along and $25 \mathrm{~cm}$ across from the cutting face (see Fig. 5). The practical engineering process of starting the shield machine from the shaft was not taken into consideration in the experiment. When the driving distance is equal to the width of a segment, the lining segments and grouting are fitted in the tunnel at the tail of the model shield machine.

The study is focused on the sandy cobble strata. In fact, mechanical properties of real gravel are not fixed values, and they change in a certain range. The most similarity criteria between prototype and model test in the paper have been fulfilled in this research. The test bin was filled with sandy soil which was prepared based on the similarity principle. The material parameters of the soil can be modified by adding coal flash and machine oil. The sand and coal flash constitute the coarse and fine particles of the test soil. The proportion of sand and coal flash determines the granular composition and friction angle of the test soil. Machine oil mainly affects the cohesion force and friction angle. To determine the material parameters of the test soil, shear tests with various ratios of soil components were carried out to create the required test soil for the experiment. The material parameters used in the test are shown in Table 2.

To apply the EPB model shield machine in sandy stratum, soil conditioning is required [18]. Furthermore, excavated soil is easier to remove after it has been conditioned [19]. In our experiment, the test soil is simple to prepare and easy to excavate. By injecting pure water with surfactant to the test bin, the soil is more easily excavated and removed.

\subsection{Model spread foundation}

In the prototype, the spread foundation is reinforced with grade C30 concrete. The spread foundation model was made of gypsum and reinforced by fine iron wire to satisfy the similarity requirements. The tensile stiffness $E A$ of the model, where $E$ is the elastic modulus and $A$ the section area, was set to meet the similarity relationship of $C_{L}^{3}$. The material parameters of the prototype and model are shown in Table 3, and the dimensions and reinforcement of the spread foundation are shown in Fig. 6.

In the experiment, the displacements of the spread foundation were tested. This included the settlement at the four corners, the horizontal displacement in the cross section, and the displacement along the driving direction. Because of the limitations of the test bin dimensions, only the spread foundation was studied in the test, ignoring the constraint of the building on top. As the main purpose of the spread foundation is to provide vertical support, the action of the building is equal to a force $(\mathrm{N})$ acting vertically on the top of the foundation. According to the
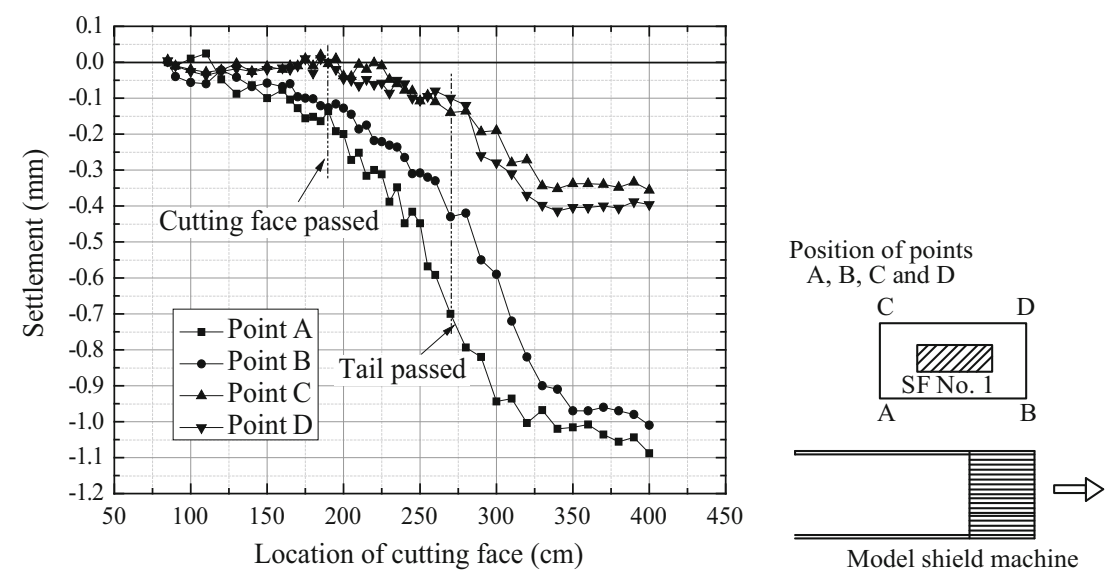

Fig. 10 Settlement of SP No.1 during the excavation 

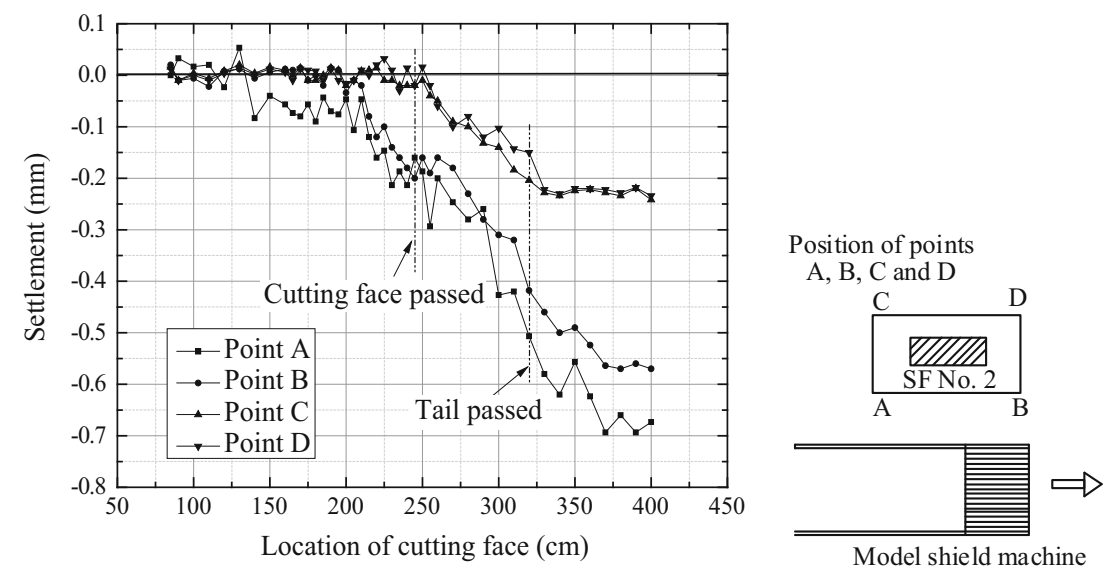

Fig. 11 Settlement of SP No.2 during the excavation

Table 4 Uneven settlement of the spread foundation

\begin{tabular}{lcr}
\hline & SF No. 1 & SF No. 2 \\
\hline (a) Cutting face passed & & \\
Minimum settlement (mm) & 0.05 & -0.03 \\
Maximum settlement (mm) & -0.16 & -0.19 \\
Declivity ratio (\%) & 0.11 & 0.08 \\
(b) Tail passed & & \\
Minimum settlement (mm) & 0.34 & -0.28 \\
Maximum settlement (mm) & -0.70 & -0.51 \\
Declivity ratio (\%) & 0.18 & 0.12 \\
(c) Tunnel excavation finished & & -0.33 \\
Minimum settlement (mm) & -0.51 & -0.67 \\
Maximum settlement (mm) & -1.09 & 0.17 \\
Declivity ratio (\%) & 0.29 & \\
\hline
\end{tabular}

similarity relationship $C_{F}=C_{L}^{3}$, the load acting on the model spread foundation is $497.7 \mathrm{~N}$. The actual load in the experiment is set to $500 \mathrm{~N}$ (Fig. 7).

\subsection{Displacement of spread foundation caused} by shield tunnel driving

When the model shield machine started to advance, the cutting face was located $85 \mathrm{~cm}$ from the edge of the bin. The machine moved forward by $315 \mathrm{~cm}$ bringing the cutting face's position to $400 \mathrm{~cm}$ from the bin edge. The horizontal displacements in the transverse section of the spread foundation varied with the driving of the model shield (Fig. 8). When the model shield machine passed by the spread foundation, the foundation had a tendency to move in the driving direction because of the ground movement. SF No. 1 showed greater displacement than SF No. 2 because it was closer to the tunnel. When the cutting face passed SF No. 1, its displacement was $-0.14 \mathrm{~mm}$, and when the tail passed it, the displacement was $-0.22 \mathrm{~mm}$. When the cutting face and tail passed SF No. 2, the displacements were both $-0.13 \mathrm{~mm}$. In general, the horizontal displacement is small and is the largest when the cutting face passes close to the foundation.

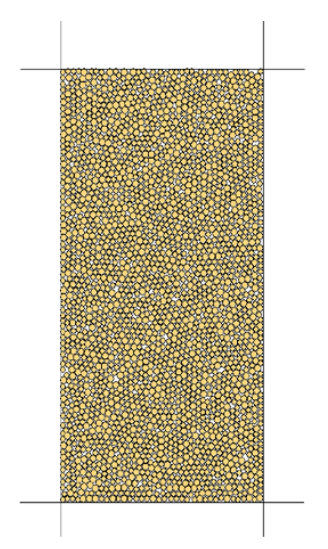

(a)

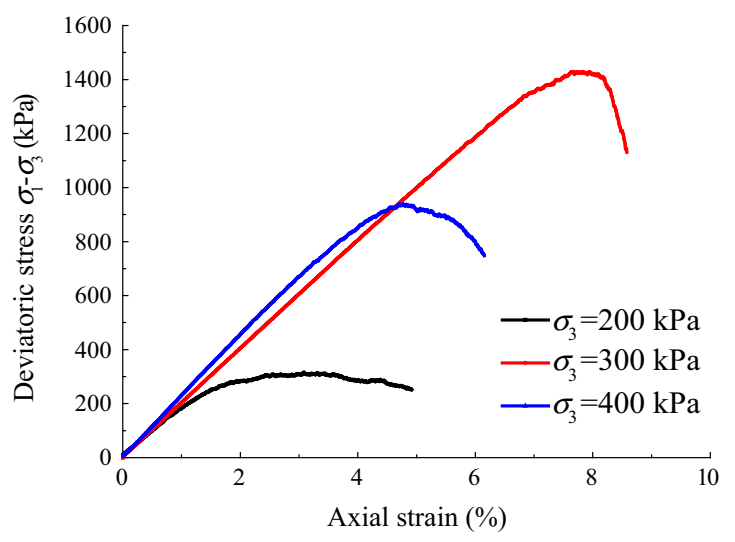

(b)

Fig. 12 Ground parameters calibration: a Calibration model. b Stress-strain curve for slightly dense cobble 
Table 5 PFC parameters of strata after calibration

\begin{tabular}{llll}
\hline & Filling & Slightly dense cobble & Medium dense cobble \\
\hline Minimum radius of particle $(\mathrm{m})$ & 0.05 & 0.05 & 0.05 \\
Ratio of max. to min. radius & 1.4 & 1.4 & 1.4 \\
Normal contact stiffness (MPa) & 8. & 24 & 34 \\
Ratio of normal to shear stiffness & 1.5 & 1.8 & 1.3 \\
Friction coefficient & 0.3 & 1.2 & 1.35 \\
Density $\left(\mathrm{kg} / \mathrm{m}^{3}\right)$ & 2,630 & 2,930 & 3,330 \\
\hline
\end{tabular}

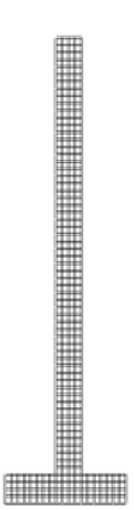

(a)

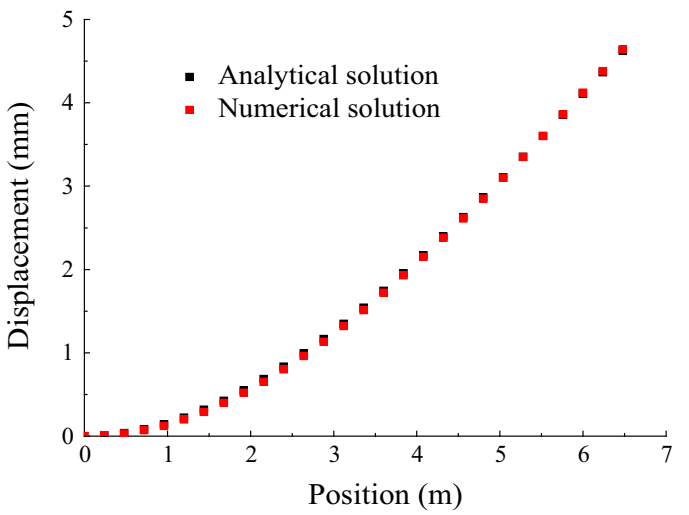

(b)
Fig. 13 Calibration of spread foundation: a Calibration model. b Deformation of the foundation

Table 6 PFC parameters of spread foundation

\begin{tabular}{ll}
\hline Parameters & Value \\
\hline Parallel-bond radius & 1.0 \\
Parallel-bond normal stiffness $(\mathrm{Pa} / \mathrm{m})$ & $5.13 \times 10^{12}$ \\
Ratio of parallel-bond normal to shear contact stiffness & 1.0 \\
Particle radius $(\mathrm{m})$ & 0.06 \\
Normal contact stiffness $(\mathrm{Pa} \cdot \mathrm{m})$ & $2.21 \times 10^{13}$ \\
Ratio of normal to shear contact stiffness & 1.36 \\
\hline
\end{tabular}

The displacement of the spread foundation along the machine driving direction is shown in Fig. 9. When the model shield machine moves forward, the soil around the shield has a tendency to move in the same direction because of the pressure that develops at the cutting face and the interaction between the shield and the ground. The displacement increases when the shield machine passes close to the spread foundation, and continues to increase until the tail passes the foundation. SF No. 1 undergoes greater displacement than SF No. 2 because it is closer to the tunnel. When the cutting face and tail passed SF No. 1, the displacements were $0.16 \mathrm{~mm}$ and $0.27 \mathrm{~mm}$, respectively. When the cutting face and tail passed SF No. 2, the displacements were $0.13 \mathrm{~mm}$ and $0.18 \mathrm{~mm}$, respectively.
The displacement along the driving direction is small, but it is greatly influenced by the thrust force of the model shield machine because most of the displacement occurs before or at the time the machine is passing close by.

Ground settlement is another important parameter used to assess the effect of shield tunnel construction on spread foundation. Settlements at four points on the spread foundation were monitored. Both SF No. 1 and No. 2 experienced maximum settlement at the side closest to the tunnel and minimum at the other side (Fig. 10). As the shield machine advanced, the settlement of the spread foundation increased. The settlements of SF No. 1 and No. 2 at points A, B, C, and D during the excavation are shown in Figs. 10 and 11 , respectively. The settlement is greater than the horizontal and longitudinal displacement. The maximum settlement occurred at point A for both SF No. 1 and No. 2. When the cutting face and tail passed SF No. 1, the settlements were -0.19 and $-0.70 \mathrm{~mm}$, respectively. When the cutting face and tail passed SF No. 2, smaller settlements of -0.18 and $-0.51 \mathrm{~mm}$ were observed. Hence, when the distance to the tunnel was shorter, the settlement increased. After the shield driving finished, the maximum settlements at SF No. 1 and No. 2 were 1.09 and $0.67 \mathrm{~mm}$, respectively. With a scaling ratio of displacement $C_{L}=12$, this is equivalent to settlements of 13.08 and $8.04 \mathrm{~mm}$, respectively, in the prototype.

Most of the settlement occurred during or after the shield machine passed. This indicates that the ground volume loss at the shield tail is an important factor in the ground settlement process around the tunnel. The test results show that uneven settlement at the bottom of the spread foundation will occur during the construction of the shield tunnel, as shown in Table 4 . When the tunnel construction ends, the uneven settlement reaches its maximum. The uneven settlement of SF No. 1 is greater than that of SF No. 2 because SF No. 1 is located closer to the tunnel.

\section{Numerical model}

Because of the limitations of the test conditions, it was difficult to simulate the discreteness of sandy cobble strata in the model test. Therefore, a numerical method of PFC 


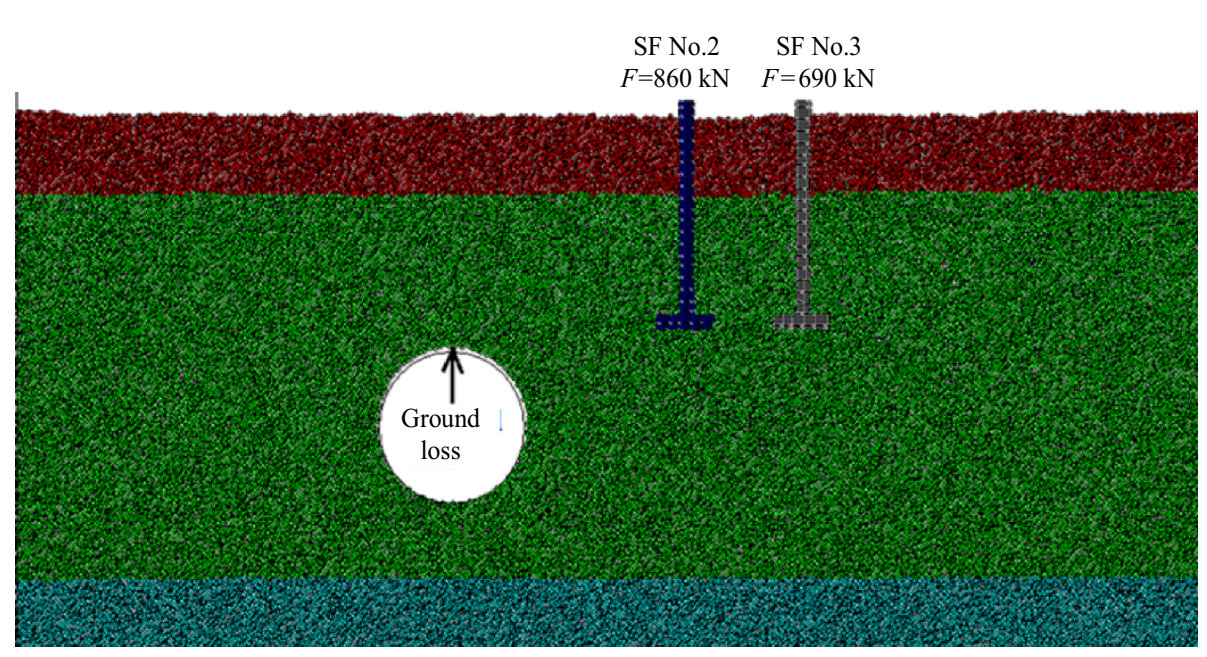

Fig. 14 PFC model

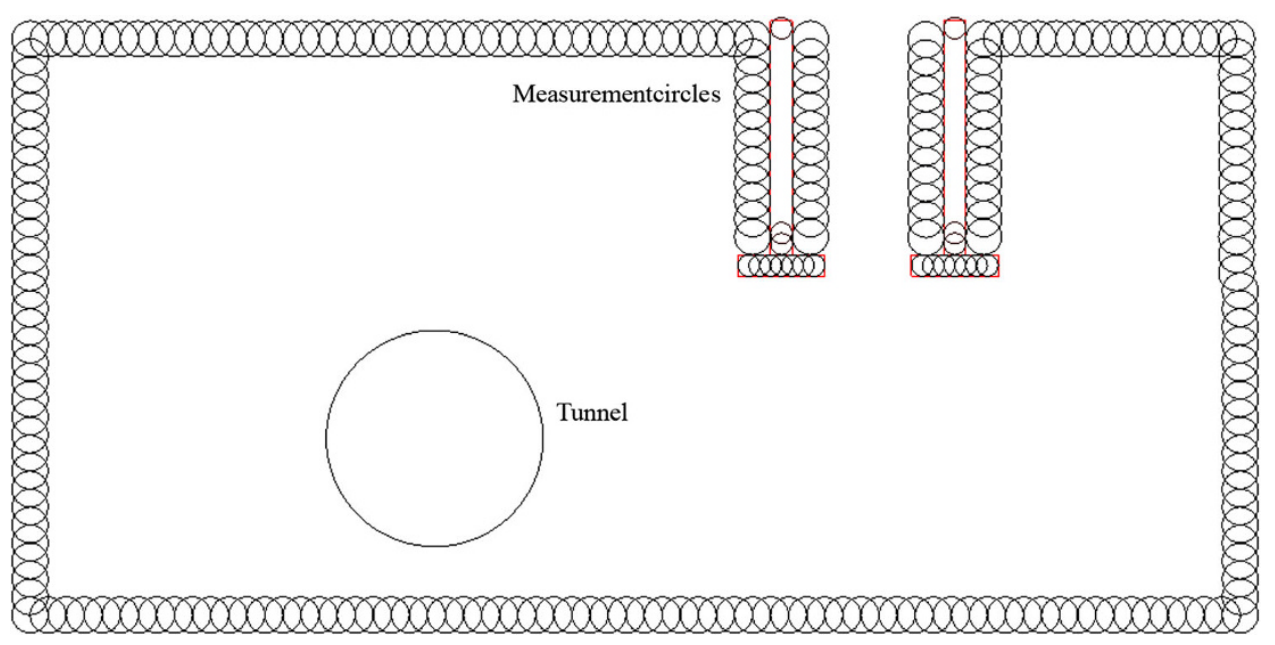

Fig. 15 Layout of measurement circles

was adopted to study the influence of the tunnel excavation on the adjacent spread foundation. In PFC, the ground can be simulated by many discrete rigid circular particles. Each particle interacts with others according to a contact relationship. Unlike the continuous mode, mesoscopic parameters in PFC cannot adopt the macroscopic mechanical material parameters directly. The parameters need to be calibrated before being used in the numerical simulation.

\subsection{Parameter calibration}

A biaxial test was carried out to calibrate the mesoscopic parameters of the ground. The test included three main steps: specimen generation, solidification, and load application. The calibration model comprised four walls filled with particles. Loads were applied at the top and bottom of the walls. By controlling the velocity of the side walls, the confining pressure of the specimen could be kept constant.
The model dimensions are $6 \times 12 \mathrm{~m}$. There are 5,538 particles with radii in the range of $0.05-0.07 \mathrm{~m}$ (Fig. 12). A trial-and-error process was used to find a set of microscopic parameters. If the macroscopic mechanical responses (cohesion, friction angle, Poisson's ratio, etc.) of the calibrated specimen agree with those of the real soil, then a suitable set of parameters is chosen.

Three types of layers were considered in the shield tunnel construction modeling: artificial filling, sandy cobble stratum, and mudstone. The macroscopic mechanical parameters of each type are shown in Table 1, and the mesoscopic parameters after calibration are shown in Table 5.

As the mesoscopic parameters of the spread foundation are different from those of the soils, the biaxial test could not be used. The spread foundation can be envisioned as an elastic column connected by a parallel bond. By applying a load at the top of the foundation, the deformation was 


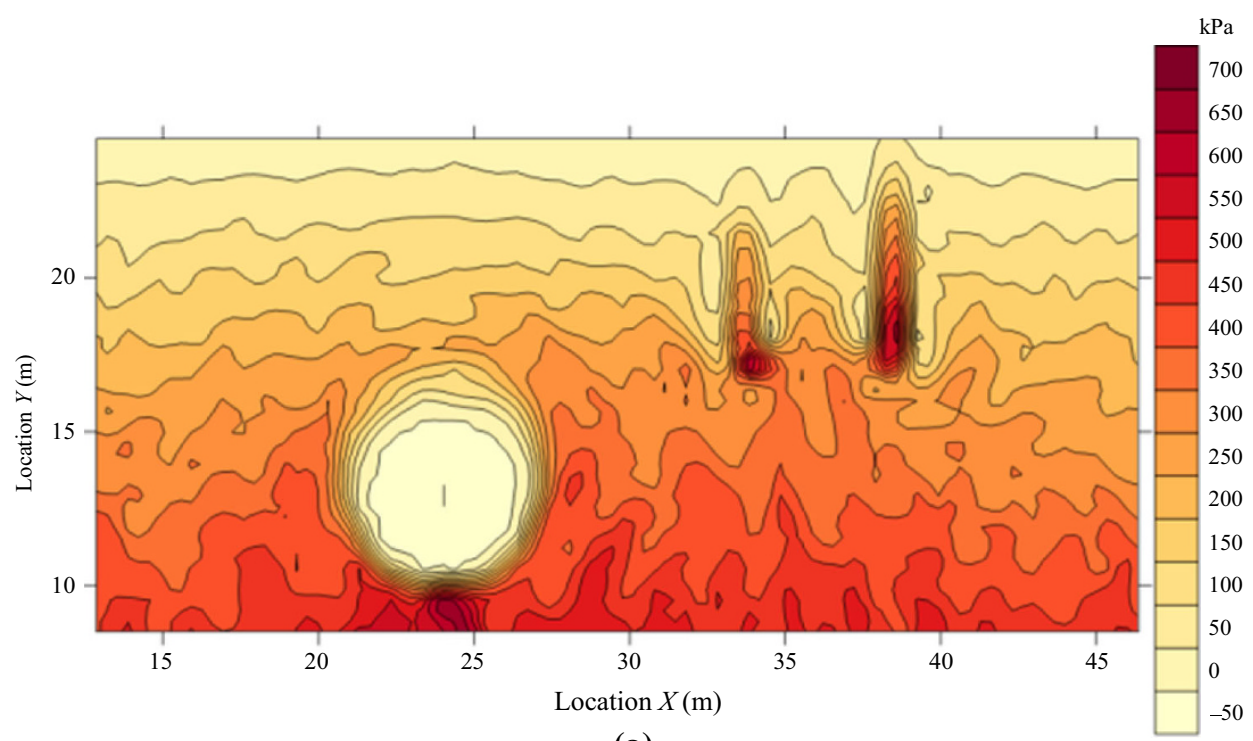

(a)

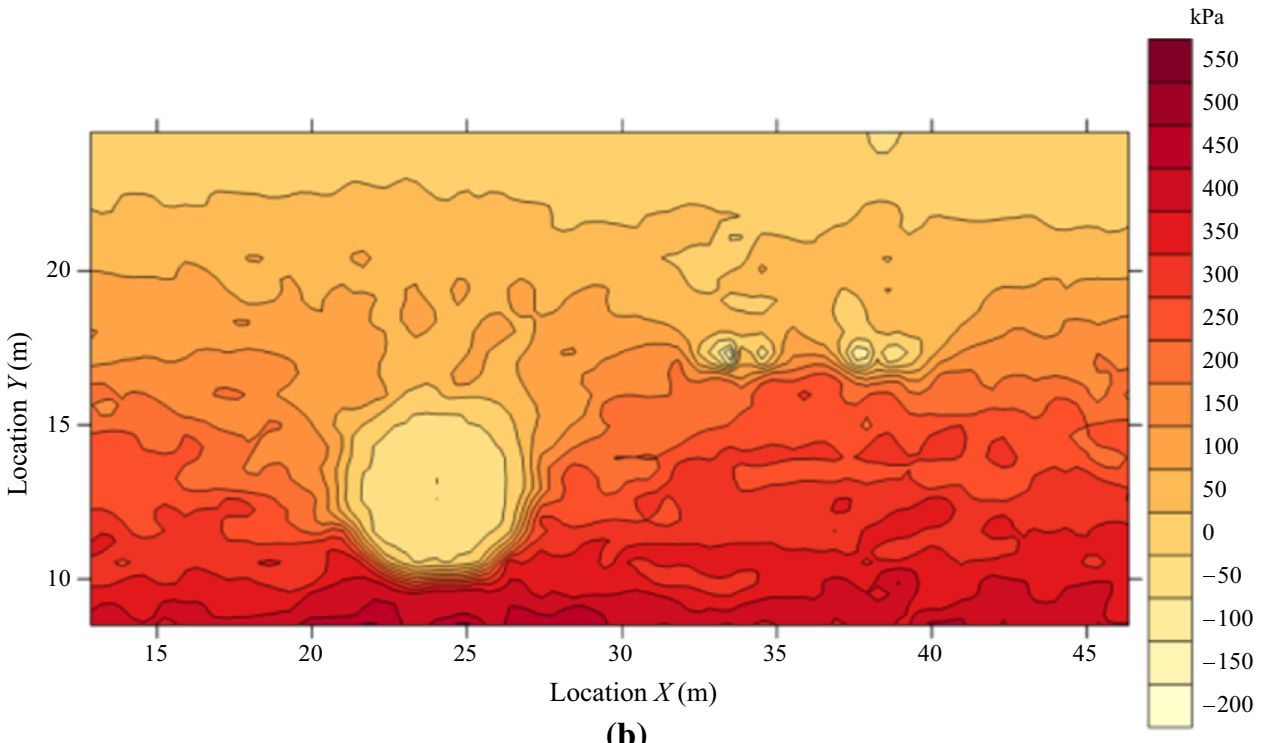

(b)

Fig. 16 Contour map of principal stress when $\delta$ is $3.36 \%$ : a Maximum principal stress. b Minimum principal stress

calculated and compared to that obtained by the analytic solution, completing the mesoscopic parameter calibration. The model consisted of 400 particles each of radius $0.06 \mathrm{~m}$ (Fig. 13). The mesoscopic parameters of the spread foundation used in the PFC are shown in Table 6.

\subsection{PFC model and measurement circles}

For the simulation, a PFC model, $52 \times 22 \mathrm{~m}$, filled with 88,001 particles, was created. SF No. 2 was positioned at $5.4 \mathrm{~m}$ from the tunnel with a load of $860 \mathrm{kN}$. Another spread foundation, SF No. 3 was added in the numerical model $9.0 \mathrm{~m}$ from the tunnel with a load of $690 \mathrm{kN}, 20 \%$ less than that on SF No. 2 (Fig. 14).
Ground volume loss is considered the main factor causing ground movement. Ground volume loss can be applied to estimate ground surface settlement [20-22]. The ground loss is determined by

$V_{\text {loss }}=V_{\text {exc }}-V_{\text {tun }}$,

and the ground volume loss ratio is given by

$\delta=\frac{V_{\mathrm{exc}}-\mathrm{V}_{\mathrm{tun}}}{V_{\mathrm{tun}}} \times 100 \%$,

where $V_{\text {loss }}$ is the ground volume loss, $\delta$ is the ground volume loss ratio, $V_{\text {exc }}$ is the ground volume excavated by the shield tunnel, and $V_{\text {tun }}$ is the volume of the tunnel space. Ground volume loss induces the ground movement 


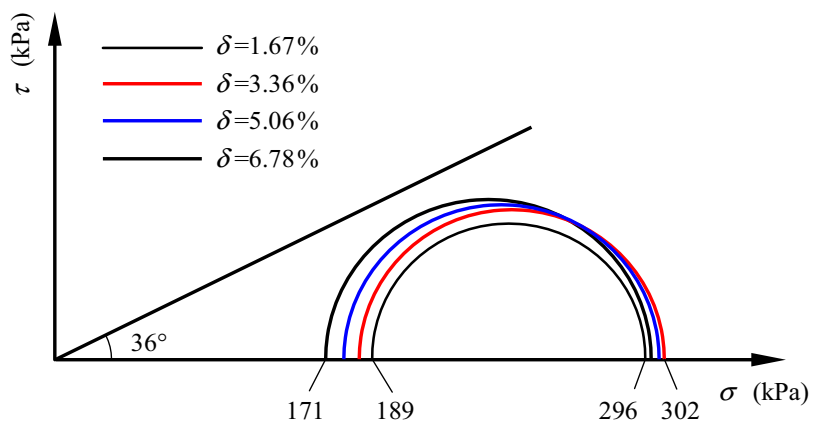

(a)

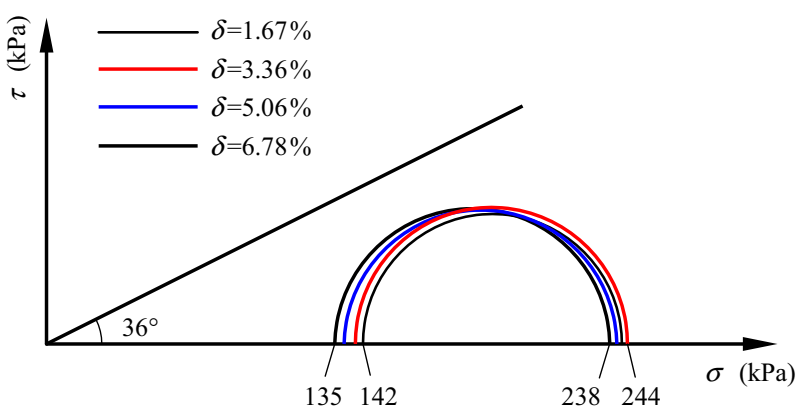

(b)

Fig. 17 Mohr-Coulomb curve of the four cases: a Ground under SF No. 2. b Ground under SF No. 3

and surface settlement. In general, a ground volume loss ratio of about $1 \%$ will cause ground surface settlement. However, in sandy cobble stratum, over-excavation at the cutting face is very common. In these cases, the volume loss ratio is usually much higher than $1 \%$. Therefore, in the simulation, four cases are considered:

$\delta=1.68 \%, \delta=3.36 \%, \delta=5.06 \%, \delta=6.78 \%$.

To calculate the influence of the tunnel construction on the spread foundation, measurement circles were defined as shown in Fig. 15.

\subsection{Stress distribution around the foundation}

After calculating the four cases, the ground stresses in the measurement circles were taken and then converted to principal stresses, thus obtaining the principal contour map for all the cases. The contour map of the principal stresses with a ground loss ratio of $\delta=3.36 \%$ is shown in Fig. 16 . The stress concentration is clearly seen at the bottom of the spread foundation because of the load on the top. The greater the load, the higher the stress concentration; thus, the stress distribution in the ground under the spread foundation is the main factor affecting the stability of the ground around the tunnel and the spread foundation. The excavation by the shield tunnel changes the stress
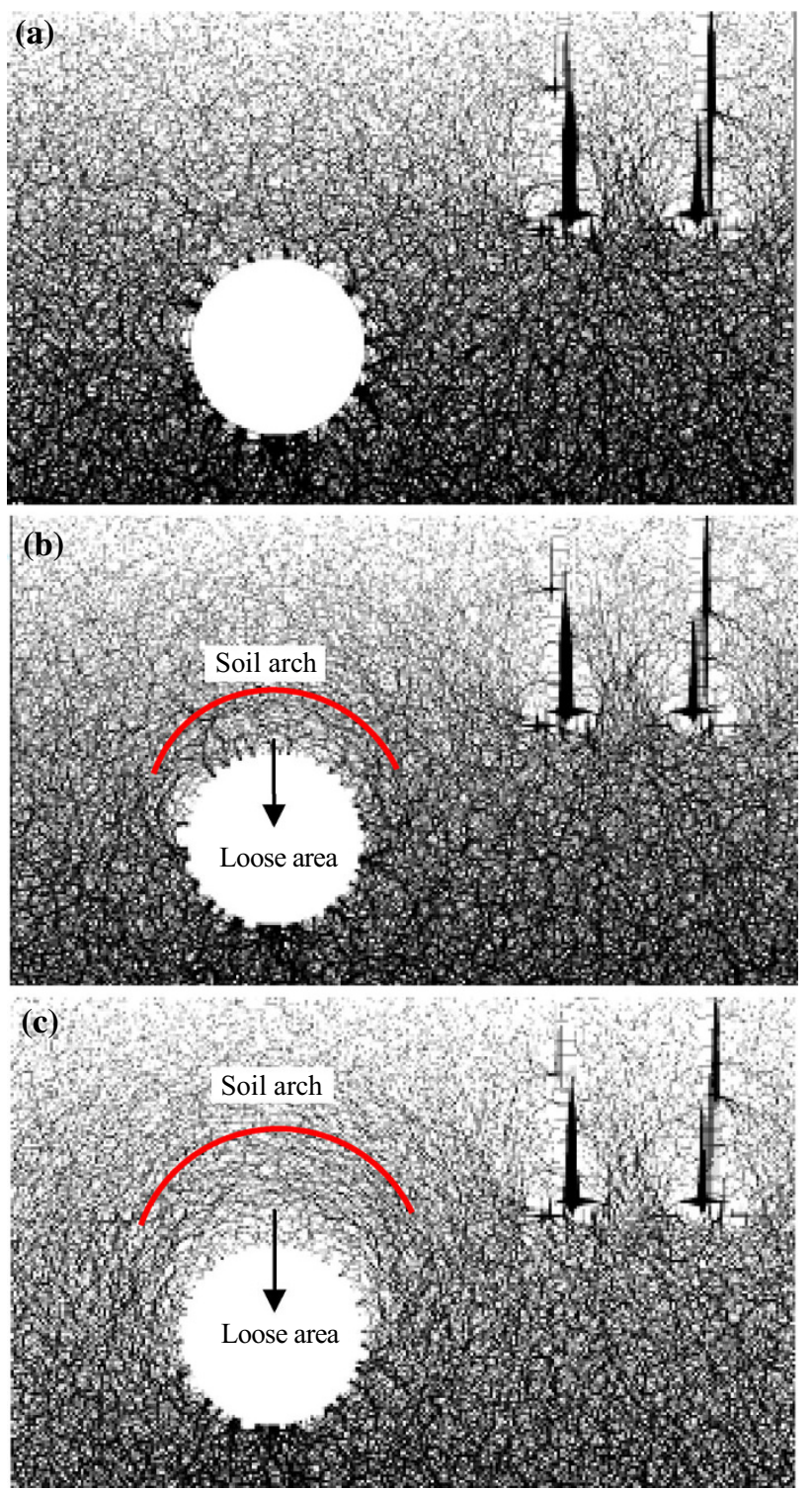

Fig. 18 Contact force chain of ground particles: a $\delta=1.68 \%$. b $\delta=3.36 \%$. c $\delta=6.78 \%$

distribution of the ground under the spread foundation. Even after the numerical stabilization, the ground stress is still different from that before the excavation.

When the ground loss ratio $\delta$ was $1.68 \%$, the maximum and minimum principal stresses changed little during or after the shield tunnel was excavated. As the ground loss ratio increased, the change in the ground principal stress was greater and it took longer to stabilize. In all the four cases, as in the case of $\delta=3.36 \%$, both SF No. 2 and No. 3 experienced the biggest maximum principal stress. For the minimum principal stress, both SF No. 2 and No. 3 experienced smaller minimum principal stresses as the ground loss ratio grew larger. 


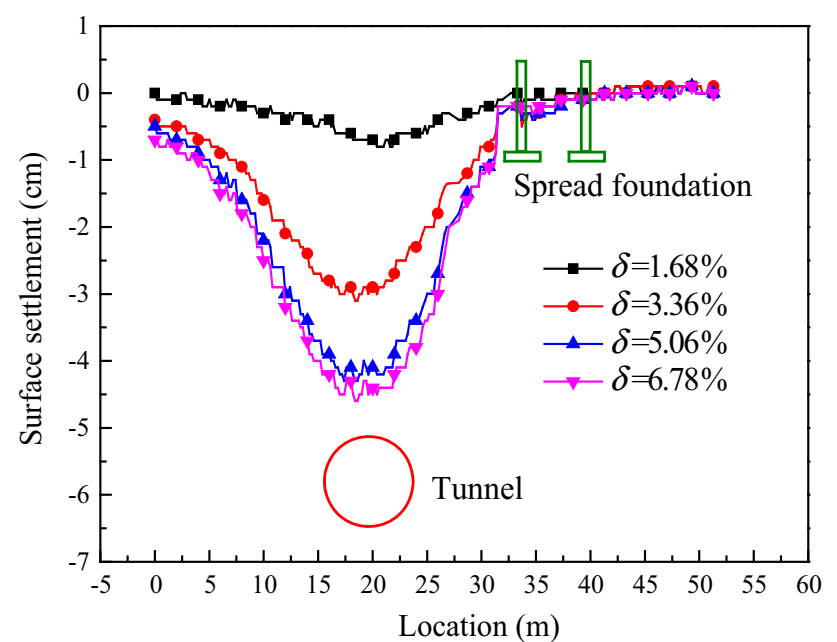

Fig. 19 Surface settlement above tunnel

Table 7 Settlements at the bottom of SF No. 2 and SF No. 3 (unit: $\mathrm{mm})$

\begin{tabular}{|c|c|c|c|c|}
\hline \multirow{2}{*}{$\begin{array}{l}\text { Ground volume loss ratio } \delta \\
(\%)\end{array}$} & \multicolumn{2}{|c|}{ SF No. 2} & \multicolumn{2}{|c|}{ SF No. 3} \\
\hline & $\begin{array}{l}\text { Close } \\
\text { side }\end{array}$ & $\begin{array}{l}\text { Far } \\
\text { side }\end{array}$ & $\begin{array}{l}\text { Close } \\
\text { side }\end{array}$ & $\begin{array}{l}\text { Far } \\
\text { side }\end{array}$ \\
\hline 1.68 & 5 & 3 & 2 & 1 \\
\hline 3.36 & 13 & 9 & 4 & 2 \\
\hline 5.06 & 15 & 11 & 5 & 3 \\
\hline 6.78 & 14 & 11 & 5 & 3 \\
\hline
\end{tabular}

Mohr-Coulomb curves of the four cases are drawn for SF No. 2 and No. 3 based on the principal stress after stabilization (Fig. 17). When the ground loss ratio increased, the Mohr circle of ground stress under the spread foundation moved to the left, closer to the ground failure line. The state of the ground stress under SF No. 3 is more favorable than that of No. 2 because SF No. 3 sustains fewer loads above it and is further away from the tunnel. Thus, shield tunnel excavation close to the spread foundation changes the ground stress state and can lead to the instability and failure in the ground under the spread foundation.

The contact force chain of ground particles for three different ground loss ratios is shown in Fig. 18. When $\delta=1.68 \%$, the ground disturbance caused by the shield tunnel construction is still weak. For $\delta=3.36 \%$ and $\delta=6.78 \%$, the redistribution of the contact force is clearly observed. A loose area appears in the dome of the tunnel where the contact force decreases. The contact force increases above the loose area, forming an arch-shaped area in the soil which prevents the loose area from expanding to the ground surface. In addition, on the top of the spread foundation, the contact force at the side closer to the tunnel is smaller than that at the other side, and at the bottom of the spread foundation, the contact force on the left is bigger than that on the right. Thus, the shield tunnel excavation changes the pressure distribution around the spread foundation.

\subsection{Ground settlement}

The surface settlements in sandy cobble stratum caused by shield tunnel excavation at various ground volume loss ratios are shown in Fig. 19. For $\delta=1.68 \%, 3.36 \%$, $5.06 \%$, and $6.78 \%$, the maximum settlements on the surface are $8,31,43$, and $45 \mathrm{~mm}$, respectively. If $\delta<5 \%$, the ground volume loss has a great effect on the maximum surface settlement. If $\delta>5 \%$, the ground volume loss has a minimal effect on the surface settlement.

The ground settlements at the bottom of SF No. 2 and SF No. 3 for four values of ground volume loss are listed in Table 7. When $\delta$ increases from $1.68 \%$ to $3.36 \%$, the settlement of the spread foundation increases significantly. For $\delta>5 \%$, the spread foundation settlement increases slightly. Thus, as shown in the previous section, the formation of the soil arch prevents the spread foundation from further settlement.

At the end of the tunnel excavation experiment, the maximum settlement of SF No. 2 on the side closer to the tunnel was about $8 \mathrm{~mm}$. The numerical analysis shows that when the ground surface settlement is about $30 \mathrm{~mm}$, which is the allowable settlement in an urban area, the maximum settlement at SF No. 2 on the side close to the tunnel is about $13 \mathrm{~mm}$. The main reason for the spread foundation settlement in the model test being smaller than that in the numerical analysis is that in the model test, the ground volume loss is well controlled. Therefore, the best way to decrease the excavation effects on the adjacent spread foundation is to decrease the ground volume loss ratio to within a reasonable value such as $3.36 \%$.

\section{Conclusions}

Model testing procedures in the laboratory and a numerical particle flow simulation method were adopted to study the effects of shield tunnel construction on neighboring spread foundation in sandy cobble strata. Our conclusions are as follows:

(1) Displacement of the foundation in the horizontal and longitudinal directions as well as vertical ground settlement occurs when the shield tunneling machine passes close to the foundation. In general, the closer the distance between the foundation and the tunnel, the greater the displacement or settlement will be. The horizontal displacement is small and achieves the 
greatest value when the cutting face passes close by. The displacement along the machine driving direction is bigger than that in the horizontal direction. It is affected significantly by the thrust force of the shield machine because most of the displacement occurs during or before the shield machine passes. Most of the ground settlement and its maximum magnitude occurred during or after the shield machine passed. Uneven settlement at the bottom of the spread foundation occurred during the excavation and peaked after the driving finished. The shorter the distance to the tunnel, the larger the uneven settlement will be.

(2) The ground stress and particle contact force changed during the shield tunnel excavation. Stress concentration can be clearly seen at the bottom of the spread foundation, caused by the load above the foundation. Increasing the ground loss ratio $\delta$ causes greater disturbance to the ground principal stress and the ground becomes more unstable. A loose area appears in the dome of the tunnel where the contact force decreases. An arch-shaped area of soil forms where the contact force increases above the loose area. The soil arch prevents the loose area from expanding to the ground surface. Shield tunnel excavation also changed the pressure distribution around the spread foundation.

Acknowledgments This paper was funded by the National Natural Science Foundation of China (Nos. 51278422 and 50925830); the National 973 Plan Topics of China (No. 2010CB732105); the National Science and Technology Pillar Program of China (No. 2012BAG05B03); and the Sichuan Youth Science and Technology Foundation, China (No. 2012JQ0021).

Open Access This article is distributed under the terms of the Creative Commons Attribution License which permits any use, distribution, and reproduction in any medium, provided the original author(s) and the source are credited.

\section{References}

1. Peck RB (1969) Deep excavations and tunneling in soft ground, state of the art report. In: Proceedings of 7 th Int. Conf. on Soil Mechanics and Foundation Engineering. Mexico City, pp 225-290

2. Sagaseta C (1987) Analysis of undrained soil deformation due to ground loss. Geotechnique 37(3):301-320

3. Verruijt A, Booker JR (1996) Surface settlements due to deformation of a tunnel in an elastic half plane. Geotechnique 46(4):753-756
4. Ma KS, Ding LY (2008) Finite element analysis of tunnel- soilbuilding interaction using displacement controlled model. WSEAS Trans Appl Theor Mech 3(3):73-82

5. Huang MS, Zhang CR, Li Z (2009) A simplified analysis method for the influence of tunneling on grouped piles. Tunn Undergr Space Technol 24(4):410-422

6. Chen RP, Zhu J, Liu W, Tang XW (2011) Ground movement induced by parallel EPB tunnels in silty soils. Tunn Undergr Space Technol 26(1):163-171

7. Bolton MD, Lu YC, Sharma JS (1996) Centrifuge models of tunnel construction and compensation grouting. In: Mair, Talor (eds) Int. Symp. on Geotech. Aspects of Underground Constr. in Soft Ground. Balkma, Rotterdam, pp 471-476

8. Nomoto T, Imamura S, Hagiwara T et al (1999) Shield tunnel construction in centrifuge. $J$ Geotech Geoenviron Eng 125(4):289-300

9. Loganathan N, Poulos HG, Stewart DP (2000) Centrifuge model testing of tunneling-ground and pile deformations. Geotechnique 50(3):283-294

10. Kim SH, Burd HJ, Milligan GWE (1998) Model testing of closely spaced tunnels in clay. Geotechnique 48(3):375-388

11. Lu Q, Fu DM (2006) Research on torque of cutter head for earth pressure balance shield with simulating experimental. Chin J Rock Mech Eng 25(S1):3137-3143 (in Chinese)

12. Zhu HH, Xu QW et al (2006) Experimental study on working parameters of EPB shield machine. Chin J Geotech Eng 28(5):553-557 (in Chinese)

13. Maynar MJ, Rodríguez LE (2005) Discrete numerical model for analysis of earth pressure balance tunnel excavation. J Geotech Geoenviron Eng 131(10):1234-1242

14. Chen RP, Tang LJ, Ling DS, Chen YM (2011) Face stability analysis of shallow shield tunnels in dry sandy ground using the discrete element method. Comput Geotech 38(2):187-195

15. Zhang ZX, Hua XY, Scott KD (2011) A discrete numerical approach for modeling face stability in slurry shield tunnelling in soft soils. Comput Geotech 38(1):94-104

16. He C, Jiang YC, Fang Y et al (2013) Impact of shield tunneling on adjacent pile foundation in sandy cobble strata. Adv Struct Eng 16(8):1457-1467

17. Thewes M, Budach C (2009) Grouting of the annual gap in shield tunneling- and important factor for minimization of settlement and production performance. In: Proceedings of ITA-AITES World Tunnel Congress, Budapest, Hungary, 23-28 May 1999

18. Vinaia R, Oggeria C, Peila D (2008) Soil conditioning of sand for EPB applications: a laboratory research. Tunn Undergr Space Technol 23(3):308-317

19. Peila D, Oggeri C, Vinai R (2007) Screw conveyor device for laboratory tests on conditioned soil for EPB tunneling operations. J Geotech Geoenviron Eng 133(12):1622-1625

20. Lee KM, Rowe RK, Lo KY (1992) Subsidence owing to tunnelling. I. Estimating the gap parameter. Can Geotech J 29(6):929-940

21. Liao SM, Liu JH, Wang RL, Lia ZM (2009) Shield tunneling and environment protection in Shanghai soft ground. Tunn Undergr Space Technol 24(4):454-465

22. Melis M, Medina L, Rodríguez JM (2002) Prediction and analysis of subsidence induced by shield tunnelling in the Madrid Metro extension. Can Geotech J 39(6):1273-1287 